\title{
Twelve Tips for Working from Home
}

\author{
Sandra Lopez-Leon, MD, PhD (1,4); Diego A. Forero, MD, PhD (2,3); \\ Paola Ruiz-Díaz, MD, MSc (2)
}

1. Global Drug Development, Novartis Pharmaceuticals Corporation, East Hanover NJ, USA.

2. Health and Sport Sciences Research Group, School of Health and Sport Sciences, Fundación Universitaria del Área Andina, Bogotá, Colombia.

3. MSc Program in Epidemiology, School of Health and Sport Sciences, Fundación Universitaria del Área Andina, Bogotá, Colombia.

4. Corresponding Author: Dr. Sandra Lopez-Leon, MD, PhD. Global Drug Development, Novartis Pharmaceuticals Corporation, East Hanover NJ, USA. Email: Sandra.lopez@novartis.com

Number of Words in Abstract: 106

Number of Words in Body of Manuscript: 2272

\section{Preprint submitted to EdArXiv}




\begin{abstract}
There is a growing trend around the globe for more people working from home. Although it is widely implemented in a number of countries and types of companies, it has shown to have multiple challenges. In this article, we provide twelve tips on how to work from home. The twelve tips are: Create Routines, Be Organized. Have An Adequate Home Office, Be Productive, Be responsible, Avoid Extreme Multitasking, Facilitate Communication and Networking, Be Balanced, Use Available Computer Programs and Platforms, Be Creative with Remote Teaching, Explore Options for Remote Research and Learn from the challenges. These tips would help students, professors and researchers around the globe.
\end{abstract}

Keywords: Remote Teaching; Innovation; Work Environments; Global Health; Education. 


\section{Introduction}

There is a growing trend around the globe for more people working from home (van der Lippe \& Lippenyi, 2020). Although it is widely implemented in a number of countries and types of companies, it has shown to have multiple challenges (Shepherd-Banigan, Bell, Basu, BoothLaForce, \& Harris, 2016; van der Lippe \& Lippenyi, 2020). In the field of medical education, working from home has its particular issues and needs (Eva, 2020). We now have the technology to be constantly connected to each other, and we can attend meetings and classes with hundreds of people in all parts of the world (Gichora et al., 2010). We will need to use time in a wise and productive manner, in order to keep track of the latest advances in science and at the same time become more productive and creative and to stay healthy and happy. In this article, we provide twelve tips on how to work from home and it would help students, professors and researchers

\section{Tip 1. Create Routines.}

Whether you live alone or with other people, it is essential that you and each member of the house, including children, has a routine and schedule. Establishing a solid routine is the key to succeed. It is essential not to confuse flexibility with a complete lack of routine. Routine is essential to be quite organized and to be more productive. In general: wake up at the same time every day and go to bed at the same time to help regulate your circadian rhythms. Your internal clock affects everything from mood to diet to heart function (Heyde, Kiehn, \& Oster, 2018). Making indoor exercise at specific hours is helpful for physical health and for forming habits. Trying to continue with your general regular routine can bring a sense of normality to your day and will avoid that have inappropriate working times. Closing your computer, leaving your desk and locking your home office helps you stay away from work in your free time too. As studies have shown that 
actions become habit after 2 weeks of routine, setting reminders as alarms might be helpful in those first two weeks.

\section{Tip 2. Be Organized.}

Organization is key to productivity and for the good use of time. It is helpful to keep 'to do lists' and to update them daily. One list can be of things you have to complete the same day, and another list for the tasks that need to be finished later in the week. Every time you complete a task, strikethrough in the list. If in the middle of productive work you remember you have to do something, or someone asks you to do a task, add it to your list. Do not stop working until you finish what you were doing and if you have an idea write it down in another list. As some people might need help with tracking time, setting an alarm or using apps might be helpful. The combination of working from home and parenting has their own challenges, depending on the stage of the child and the gender of the working parent (Lin \& Burgard, 2018; Lopez-Leon, Del Valle, Salceda, Villegas-Pichardo, \& Scosyrev, 2019; Ohu et al., 2019). Keep in mind that there are other activities in which you will have to invest your time, such as preparing food, taking care of children or cleaning. Create agreements with all the members of the family to carry out the needed tasks of the home.

\section{Tip 3. Have An Adequate Home Office.}

Create a working space with a computer that is ergonomically friendly (a screen of adequate size) and with an appropriate desk. The more it resembles your workplace, the better. A second monitor would replace the need to print documents and it is important to find a space away from your bedroom to work. Studies have shown that people that use their bed to work have a higher risk of 
developing sleeping disorders (Adams et al., 2017). Make sure your working space also has a comfortable chair, good illumination and ventilation and adequate accessories (such as a good internet connection and microphone and camera). If you get easily distracted, you can use noise cancelling headphones, either to listen to music or to reduce the distracting outside noise.

\section{Tip 4. Be Productive.}

Enjoy your work, in order to maximize and prioritize productivity. Although there are global changes in productivity, your work performance will be evaluated according to how productive you have been (Forero \& Moore, 2016). Set clearly defined goals, with yourself as well as with others. The SMART goal approach can help you reach your goals, which need to be Specific, Measurable, Achievable, Realistic and Time-bound (Grant \& Dweck, 2003).

Do not check your emails the whole day, set times to do this. If you feel the need to continuously check emails, work offline. First do the work that is more challenging, taking into account that you need a mind that is not tired. If you need a break, you can check your email, which is usually not very challenging. Be flexible, as you might need to re-prioritize.

\section{Tip 5. Be responsible.}

In order to work in an adequate manner, you have to be responsible if you want to have the flexibility to set your own schedule. The first principle is to do the things you have to do, before you do the things you want to do. Knowing that you will have a reward, when you finish the things you have to do, will motivate you to keep on going. Share accountability with others. Do not overload yourself or your colleagues with a large number of meetings, focus on the most important ones (Forero \& Moore, 2016). 


\section{Tip 6. Avoid Extreme Multitasking.}

Studies have shown that if you multitask you cannot give $100 \%$ of your attention to one thing, and therefore your attention to detail diminishes (Ralph, Thomson, Cheyne, \& Smilek, 2014) increasing your chance to commit mistakes. With so many things going on at the same time, many people are trying to be multitasking. To focus on fundamental tasks (Forero \& Moore, 2016) try to diminish distractions, such as calls. Explain to children that working area is off limits and avoid interruptions unless it is important.

\section{Tip 7. Facilitate Communication and Networking.}

Being able to communicate quickly and reliable has made possible working from home. Update your manager or boss frequently and check on what the people you are supervising are working on, have regulate meetings, at least once a week. The more connected you feel with others, the more fulfillment you will feel as you go about your days working from home. If you need advice or assistance on your work, give a coworker a heads up at the beginning of the day so they can plan better. Be also open and receptive to the help others are asking from you. Continue having the same meetings you previously had.

\section{Tip 8. Be Balanced.}

In order to stay healthy, you need to have a balance in all the different areas (mental, physical, emotional, spiritual). By having a routine, organizing yourself and being productive, you will be able to have time for other things that are important. Studies have shown consistently that eating healthy, sleeping well and doing exercise decrease the risk of having mental or metabolic disorders (Maes et al., 2012; Penedo \& Dahn, 2005). If you do not take care of the needs of your body, there will be a higher possibility that the disorders you had a genetic predisposition will develop 
(Hirschhorn, Lohmueller, Byrne, \& Hirschhorn, 2002). Fresh air and natural light are good for you. Eat healthy and balanced at the same time. Getting enough and adequate sleep is one of the most important things to be productive, stay healthy and feel good. If you need a 10 minutes break, use that time to have a relaxing moment.

\section{Tip 9. Use Available Computer Programs and Platforms.}

There are multiple online platforms that facilitate the development of teleconferences, such as Skype, Slack, Zoom and Google Hangouts Meet and Microsoft teams (Yang \& Meals, 2014). Some of them are completely free and others involve the payment of a fee for full use. Shared files in Google drive are useful for collaborative online works. Applications such as WhatsApp facilitate other aspects of real-time communication with colleagues. Other apps like Toggl or Rescue Time might also be helpful. Toggle is an app that lets you manually track each task as you do it. Rescue time will automatically monitor the websites you visit, track the time you spend on meetings or answering emails and create reports for you. This app will remind you if your scheduled half hours breaks are turning into two-hour procrastination windows.

\section{Tip 10. Be Creative with Remote Teaching.}

Multiple educative institutions around the globe have had the challenge of migrating classes from the classroom to online platforms. Available learning management systems, such as Moodle and Blackboard, facilitate the development of remote teaching, including the implementation of multiple activities and evaluation (Hart, Bird, \& Farmer, 2019; Popovic, Popovic, Rovcanin Dragovic, \& Cmiljanic, 2018). In addition, these platforms have the potential of providing quantitative data about participation and interaction of students (Saiz Manzanares, Marticorena Sanchez, Garcia Osorio, \& Diez-Pastor, 2017; Saqr, Fors, \& Tedre, 2017). It also helps institutions 
to follow the development and dedication of the professors, analyzing quantitative data about the time they spend in the platforms. It is possible that professors and institutions that have previous experience with virtual teaching have less issues in the transition. In this context, use of creative approaches from professors, particularly from resource-limited environments (Garcia \& Curioso, 2008), would facilitate the fulfilling of learning objectives and the strengthening of competencies in students (Lehr \& Schlenger, 2016). Teaching of clinical or practical subjects would beneficiate from the use of virtual systems (Manesh \& Dhaliwal, 2018).

\section{Tip 11. Explore Options for Remote Research.}

A large number of laboratories around the world have their members working at home. It means, in general, a focus on activities related to the analysis of data and writing of manuscripts and future grant applications (Bourne, 2005; Bourne \& Chalupa, 2006). Those research groups that also have strong capacities in dry lab methods, such as bioinformatics or biostatistics, get a better opportunity of advancing in days of working far from the labs (Choi, Cheng, \& Greenberg, 2019; Forero, Lopez-Leon, Gonzalez-Giraldo, \& Bagos, 2019; Min, Lee, \& Yoon, 2017). The transition to remote work also highlights the importance of an adequate backup (using cloud-based services) of key files from the labs, in addition to an appropriate implementation of electronic lab notebooks and laboratory information management systems (Kwok, 2018).

\section{Tip 12. Learn from the challenges.}

Be grateful you have the option of being in a job that can have remote activities. Not everyone can and you might learn a lot from the experience. For example, there are several reflections that have brought this pandemic (Park, Cook, Lim, Sun, \& Dickens, 2020) and that would be helpful for future times: It has highlighted the importance for multiple countries of investment in adequate 
health care systems and of strong financing of public and private research and innovations systems (Forero, Majeed, \& Ruiz-Diaz, 2020; Moses et al., 2015). In addition, it highlights the impact of broad collaborations among researchers and institutions and of quick and broad delivery of key results, from an Open Science perspective (Masum et al., 2013). The transition to remote teaching has shown the importance of having the infrastructure and training for an effective use of virtual platforms in traditional academic programs. We need to systematize the lessons learned in times of crisis (Eva, 2020).

\section{Conclusions}

Working from home has several advantages and challenges. In this paper, we provide twelve tips that might be helpful for people around the world. When a person is working from home, work and family domains become interconnected and they are no longer separate spheres. It is possible that these days of pandemic (Park et al., 2020) will have an impact on the way we work from now on. Currently, the days where we could only socialize and attend large meetings in person are gone (Viglione, 2020) and the time needed to print dozens of papers to read during long commutes is being replaced by more time spent online. Working from home can be isolating, so take time to connect with your team or if you live alone speak to someone on the phone at least once a day. Enjoy working from home; you can even have lunch or coffee with colleagues using virtual meetings.

\section{Acknowledgements}

DAF has been previously supported by grants from Colciencias. 


\section{Disclosure statement}

The authors report no conflicts of interest. The authors alone are responsible for the content and writing of this article.

\section{Notes on Contributors}

Sandra Lopez-Leon, MD, PhD is a scientific researcher at Novartis Pharmaceuticals in NJ, USA. She has a Master in Science, Doctor in Science and PhD in Genetic Epidemiology from the University of Rotterdam in the Netherlands. She has 32 authored publications with a cumulative h-index of 11.

Diego A. Forero, MD, PhD is Professor and Research Leader at the Fundación Universitaria del Área Andina (Bogotá). He has been involved in the creation and modification of undergraduate and postgraduate programs and has authored 92 international scientific publications (h-index: 25).

Paola Ruiz-Díaz, MD, MSc is Dean at the Fundación Universitaria del Área Andina (Bogotá). She has been involved in the creation and modification of undergraduate and postgraduate programs in different universities in Colombia.

\section{ORCID}

Sandra Lopez-Leon http://orcid.org/0000-0001-7504-3441

Diego A. Forero http://orcid.org/0000-0001-9175-3363

Paola Ruiz-Díaz http://orcid.org/0000-0001-7620-6839 


\section{References}

Adams, R. J., Appleton, S. L., Taylor, A. W., Gill, T. K., Lang, C., McEvoy, R. D., \& Antic, N. A. (2017). Sleep health of Australian adults in 2016: results of the 2016 Sleep Health Foundation national survey. Sleep Health, 3(1), 35-42. doi:10.1016/j.sleh.2016.11.005

Bourne, P. E. (2005). Ten simple rules for getting published. PLoS Comput Biol, 1(5), e57. doi:10.1371/journal.pcbi.0010057

Bourne, P. E., \& Chalupa, L. M. (2006). Ten simple rules for getting grants. PLoS Comput Biol, 2(2), e12. doi:10.1371/journal.pcbi.0020012

Choi, A. R., Cheng, D. L., \& Greenberg, P. B. (2019). Twelve tips for medical students to conduct a systematic review. Med Teach, 41(4), 471-475. doi:10.1080/0142159X.2018.1426847

Eva, K. W. (2020). Medical Education Adaptations: Really Good Stuff for Educational Transition during a Pandemic. Med Educ. doi:10.1111/medu.14172

Forero, D. A., Lopez-Leon, S., Gonzalez-Giraldo, Y., \& Bagos, P. G. (2019). Ten simple rules for carrying out and writing meta-analyses. PLoS Comput Biol, 15(5), $e 1006922$. doi:10.1371/journal.pcbi.1006922

Forero, D. A., Majeed, M. H., \& Ruiz-Diaz, P. (2020). Current trends and future perspectives for medical education in Colombia. Med Teach, 42(1), 17-23. doi:10.1080/0142159X.2019.1659944

Forero, D. A., \& Moore, J. H. (2016). Considerations for higher efficiency and productivity in research activities. BioData Min, 9, 35. doi:10.1186/s13040-016-0115-3

Garcia, P. J., \& Curioso, W. H. (2008). Strategies for aspiring biomedical researchers in resource-limited environments. PLoS Negl Trop Dis, 2(8), e274. doi:10.1371/journal.pntd.0000274

Gichora, N. N., Fatumo, S. A., Ngara, M. V., Chelbat, N., Ramdayal, K., Opap, K. B., . . Hide, W. (2010). Ten simple rules for organizing a virtual conference--anywhere. PLoS Comput Biol, 6(2), e1000650. doi:10.1371/journal.pcbi.1000650

Grant, H., \& Dweck, C. S. (2003). Clarifying achievement goals and their impact. J Pers Soc Psychol, 85(3), 541-553. doi:10.1037/0022-3514.85.3.541

Hart, T., Bird, D., \& Farmer, R. (2019). Using blackboard collaborate, a digital web conference tool, to support nursing students placement learning: A pilot study exploring its impact. Nurse Educ Pract, 38, 72-78. doi:10.1016/j.nepr.2019.05.009

Heyde, I., Kiehn, J. T., \& Oster, H. (2018). Mutual influence of sleep and circadian clocks on physiology and cognition. Free Radic Biol Med, 119, 8-16. doi:10.1016/j.freeradbiomed.2017.11.003

Hirschhorn, J. N., Lohmueller, K., Byrne, E., \& Hirschhorn, K. (2002). A comprehensive review of genetic association studies. Genet Med, 4(2), 45-61. doi:10.1097/00125817-200203000-00002

Kwok, R. (2018). How to pick an electronic laboratory notebook. Nature, 560(7717), 269-270. doi:10.1038/d41586-018-05895-3

Lehr, S., \& Schlenger, A. (2016). Creative Strategies to Enhance Students' Classroom Learning in Mental Health. J Psychosoc Nurs Ment Health Serv, 54(5), 41-48. doi:10.3928/02793695-20160420-06

Lin, K. Y., \& Burgard, S. A. (2018). Working, Parenting and Work-Home Spillover: Gender Differences in the Work-Home Interface across the Life Course. Adv Life Course Res, 35, 24-36. doi:10.1016/j.alcr.2017.12.003

Lopez-Leon, S., Del Valle, C. A., Salceda, A. H., Villegas-Pichardo, L. O., \& Scosyrev, E. (2019). Medical Careers and Motherhood: A Cross-Sectional Study of Hispanic Female Physicians. J Grad Med Educ, 11(4 Suppl), 181-185. doi:10.4300/JGME-D-19-00439

Maes, L., Van Cauwenberghe, E., Van Lippevelde, W., Spittaels, H., De Pauw, E., Oppert, J. M., . . De Bourdeaudhuij, I. (2012). Effectiveness of workplace interventions in Europe promoting healthy eating: a systematic review. Eur J Public Health, 22(5), 677-683. doi:10.1093/eurpub/ckr098

Manesh, R., \& Dhaliwal, G. (2018). Digital Tools to Enhance Clinical Reasoning. Med Clin North Am, 102(3), 559-565. doi:10.1016/j.mcna.2017.12.015

Masum, H., Rao, A., Good, B. M., Todd, M. H., Edwards, A. M., Chan, L., . . Bourne, P. E. (2013). Ten simple rules for cultivating open science and collaborative R\&D. PLoS Comput Biol, 9(9), e1003244. doi:10.1371/journal.pcbi.1003244

Min, S., Lee, B., \& Yoon, S. (2017). Deep learning in bioinformatics. Brief Bioinform, 18(5), 851-869. doi:10.1093/bib/bbw068 
Moses, H., 3rd, Matheson, D. H., Cairns-Smith, S., George, B. P., Palisch, C., \& Dorsey, E. R. (2015). The anatomy of medical research: US and international comparisons. JAMA, 313(2), 174-189. doi:10.1001/jama.2014.15939

Ohu, E. A., Spitzmueller, C., Zhang, J., Thomas, C. L., Osezua, A., \& Yu, J. (2019). When work-family conflict hits home: Parental work-family conflict and child health. J Occup Health Psychol, 24(5), 590-601. doi:10.1037/ocp0000145

Park, M., Cook, A. R., Lim, J. T., Sun, Y., \& Dickens, B. L. (2020). A Systematic Review of COVID-19 Epidemiology Based on Current Evidence. J Clin Med, 9(4). doi:10.3390/jcm9040967

Penedo, F. J., \& Dahn, J. R. (2005). Exercise and well-being: a review of mental and physical health benefits associated with physical activity. Curr Opin Psychiatry, 18(2), 189-193. doi:10.1097/00001504200503000-00013

Popovic, N., Popovic, T., Rovcanin Dragovic, I., \& Cmiljanic, O. (2018). A Moodle-based blended learning solution for physiology education in Montenegro: a case study. Adv Physiol Educ, 42(1), 111-117. doi:10.1152/advan.00155.2017

Ralph, B. C., Thomson, D. R., Cheyne, J. A., \& Smilek, D. (2014). Media multitasking and failures of attention in everyday life. Psychol Res, 78(5), 661-669. doi:10.1007/s00426-013-0523-7

Saiz Manzanares, M. C., Marticorena Sanchez, R., Garcia Osorio, C. I., \& Diez-Pastor, J. F. (2017). How Do B-Learning and Learning Patterns Influence Learning Outcomes? Front Psychol, 8, 745. doi:10.3389/fpsyg.2017.00745

Saqr, M., Fors, U., \& Tedre, M. (2017). How learning analytics can early predict under-achieving students in a blended medical education course. Med Teach, 39(7), 757-767. doi:10.1080/0142159X.2017.1309376

Shepherd-Banigan, M., Bell, J. F., Basu, A., Booth-LaForce, C., \& Harris, J. R. (2016). Workplace Stress and Working from Home Influence Depressive Symptoms Among Employed Women with Young Children. Int J Behav Med, 23(1), 102-111. doi:10.1007/s12529-015-9482-2

van der Lippe, T., \& Lippenyi, Z. (2020). Co-workers working from home and individual and team performance. New Technol Work Employ, 35(1), 60-79. doi:10.1111/ntwe.12153

Viglione, G. (2020). A year without conferences? How the coronavirus pandemic could change research. Nature, 579(7799), 327-328. doi:10.1038/d41586-020-00786-y

Yang, P. R., \& Meals, R. A. (2014). How to establish an interactive eConference and eJournal Club. J Hand Surg Am, 39(1), 129-133. doi:10.1016/j.jhsa.2013.10.004 